\title{
Occupational Exposure to Volatile Organic Compounds and Aldehydes in the U.S. Trucking Industry
}

\author{
M. E. DAVIS ${ }^{\star}, \dagger \ddagger$, A. P. BLICHARZ $\ddagger$, J. E. HART $\ddagger, \S$, F. LADEN $\ddagger, \S$, E. GARSHICK $\S, \|$, and T. J. \\ SMITH ${ }^{\ddagger}$ \\ Department of Environmental Health, Harvard School of Public Health, 401 Park Drive, Boston, \\ Massachusetts 02215, Channing Laboratory, Brigham and Women's Hospital and Harvard Medical \\ School, 181 Longwood Avenue, Boston Massachusetts 02115, and Pulmonary and Critical Care \\ Medicine Section, VA Boston Healthcare System, 1400 VFW Parkway, West Roxbury, \\ Massachusetts 02132
}

\begin{abstract}
Diesel exhaust is a complex chemical mixture that has been linked to lung cancer mortality in a number of epidemiologic studies. However, the dose-response relationship remains largely undefined, and the specific components responsible for carcinogenicity have not been identified. Although previous focus has been on the particulate phase, diesel exhaust includes a vapor phase of numerous volatile organic compounds (VOCs) and aldehydes that are either known or suspected carcinogens, such as 1,3-butadiene, benzene, and formaldehyde. However, there are relatively few studies that quantify exposure to VOCs and aldehydes in diesel-heavy and other exhaust-related microenvironments. As part of a nationwide assessment of exposure to diesel exhaust in the trucking industry, we collected measurements of VOCs and aldehydes at 15 different U.S. trucking terminals and in city truck drivers (with 6 repeat site visits), observing average shift concentrations in truck cabs and at multiple background and work area locations within each terminal. In this paper, we characterize occupational exposure to 18 different VOCs and aldehydes, as well as relationships with particulate mass (elemental carbon in $\mathrm{PM}<1 \mu \mathrm{m}$ and $\mathrm{PM}_{2.5}$ ) across locations to determine source characteristics. Our results show that occupational exposure to VOCs and aldehydes varies significantly across the different sampling locations within each terminal, with significantly higher exposures noted in the work environments over background levels $(p<0.01)$. A structural equation model performed well in predicting terminal exposures to VOCs and aldehydes as a function of job, background levels, weather conditions, proximity to a major road, and geographic location $\left(R^{2}=\right.$ $0.2-0.4$ work area; $R^{2}=0.5-0.9$ background).
\end{abstract}

\section{Introduction}

Diesel exhaust has been linked to an increased risk of lung cancer mortality in over 35 epidemiologic studies $(1,2)$. Although diesel exhaust is considered either a definite (3) or probable human carcinogen (4-7), the specific components responsible have not been identified. Previous focus has been on the particulate phase, based on animal studies linking carcinogenicity with particulate overload in the lungs (8). However, diesel and other vehicle exhaust related to traffic are complex mixtures and include a vapor phase with numerous chemicals, some of which are either known (Group A: 1,3-butadiene and benzene) or suspected (Group B1: formaldehyde; Group B2: acetaldehyde) human carcinogens (9).

\footnotetext{
* Corresponding author e-mail: mary.davis@ umit.maine.edu; fax: (207) 581-4278.

†University of Maine.

${ }_{\text {Harvard School of Public Health. }}$

\$Brigham and Women's Hospital and Harvard Medical School.

|lvA Boston Healthcare System.
} 
The epidemiologic literature has primarily focused on diesel exhaust as a human lung carcinogen, although noncancer health effects that relate to cardiovascular disease and nonmalignant respiratory disease have been proposed $(10,11)$. Volatile organic compounds (VOCS) have also been suspected to be associated with other noncancer health effects, such as asthma, although these associations remain largely unproven (12). Despite these potentially harmful human health impacts, there are relatively few studies that quantify exposure to VOCs and aldehydes in diesel-heavy and other vehicle exhaust-related microenvironments $(13,14)$.

The primary gaseous components of diesel exhaust that we report here include olefins (1,3butadiene), aromatics (benzene, ethylbenzene, toluene, and xylenes), alkanes, and aldehydes (formaldehyde and acetaldehyde). Although these compounds are not unique to diesel exhaust, their relationship with exhaust particulate (as measured by elemental carbon in particles $<1.0$ $\mu \mathrm{m}$ in diameter, to which diesel exhaust largely contributes) should provide valuable insight into the characteristics of exposures in diesel-heavy microenvironments. The focus of this paper is to characterize occupational exposure to VOCs and aldehydes, as well as to explore their relationship with particulate mass across locations to determine source characteristics. We also construct a model predicting terminal exposures using structural equation modeling techniques.

\section{Methods and Data Collection}

As part of a nationwide assessment of exposure to diesel and traffic-related exhaust in the U.S. trucking industry, we collected simultaneous measurements of VOCs and aldehydes, as well as particulates (elemental carbon (EC) in $\mathrm{PM}<1 \mu \mathrm{m}$ and $\mathrm{PM}_{2.5}$, for which a full exposure model was presented elsewhere) $(15,16)$. EC was chosen as our primary marker of diesel exposure in this study (see refs 15 and 16 for further discussion), although its relationship with mass of diesel emissions is known to vary with operating conditions. Samples were taken in 15 different U.S. cities with 6 repeated site visits between 2004 and 2006 using both stationary work area monitors and personal in-cab truck sampling. See Table A-1, Supporting Information, for a list of these locations. The specific microenvironments sampled for VOCs and aldehydes were background conditions at the perimeter of the trucking terminal (yard), indoor work environments (loading dock and mechanic shop), and on-road in truck cabs (driver). This exposure assessment is part of the larger Trucking Industry Particulate Study (TrIPS), an epidemiologic and exposure assessment study of diesel exhaust and lung cancer mortality in four large unionized U.S. trucking companies (17), and the terminals were randomly chosen to be regionally representative of the approximately 140 eligible trucking terminals in the epidemiologic cohort.

A diagrammatic representation of a typical trucking terminal work site and stationary sampler location is provided in Figure A-1, Supporting Information. At the center of the trucking terminal is an elongated semienclosed warehouse building with a raised floor known as the loading dock, which operates $24 \mathrm{~h} /$ day, 7 days a week. Truck trailers are moved about the yard and backed up to doors on the loading dock by small diesel-powered tugs. Freight from incoming trailers is moved to outgoing trailers by dockworkers driving small liquid propane gas (LPG) powered forklifts on the loading dock. Truck tractors and trailers that have been damaged or need to be serviced are taken to an on-site mechanic shop, or if there is no shop, the repair and maintenance work is contracted with local vendors.

\section{Stationary Sampling}

Background measurements for VOCs and aldehydes were obtained from 2-4 monitors placed in the yard at the perimeter of the terminal property. The sampling locations were expanded during the last six site visits to incorporate indoor work area monitoring in the loading dock and the mechanic shop. The collectors, their pumps, and a real-time monitor for temperature 
and humidity (HOBO, Onset Computer Corp, Bourne, MA) were mounted in a box housing connected to an external battery (see Figure A-2, Supporting Information, for picture of setup). These samples were collected at consecutive $12 \mathrm{~h}$ intervals throughout each 5 day site visit and, therefore, represent $12 \mathrm{~h}$ averages of exposure levels at these locations. These background and work area samples represent stationary concentrations (yard background, loading dock, and mechanic shop) and not personal measurements (yard worker, dockworker, and mechanic).

\section{Personal Driver Sampling}

The truck transport operations are separated into customer-related local (pickup \& deliver, P\&D) and long distance between large terminals (long haul, LH) trips. Usually P\&D drivers work during the daytime and stay within a $50-100 \mathrm{~km}$ radius of the home terminal, while $\mathrm{LH}$ drivers work at night and drive many hundreds of kilometers on any given run. Since our goal was to characterize exposures of drivers in local traffic, we limited measurements of VOCs and aldehydes to $P \& D$ truck cabs. After permission was granted by the driver, the sampler was mounted on the dashboard of the passenger side (see Figure A-2, Supporting Information). Sampling was conducted in trucks selected randomly from daily P\&D driver routes to obtain an assorted sampling of trucks and route deliveries, and drivers were identified as either smokers or nonsmokers by direct interview. The sampling protocol was reviewed and approved by the Brigham and Women's Hospital, Harvard School of Public Health, and VA Boston Healthcare System Institutional Review Boards.

\section{Analytical Methods}

A full description of the analytical methods for particulates is provided elsewhere (16). Volatile hydrocarbons were collected in thermal desorption tubes with a triple sorbent: $200 \mathrm{mg}$ of Carbopack B followed by $230 \mathrm{mg}$ of Carbopack X for 1,3-butadiene, with a final $170 \mathrm{mg}$ of Carboxen 1001 for intermediate hydrocarbons passing the first two sections. The above sorbents were chosen because they allow us to minimize breakthrough and maximize both the sample volume and the range of analytes collected to include 1,3-butadiene (18). A flow rate of $10-40 \mathrm{~mL} / \mathrm{min}$ (depending on the sampler) was used to extend the duration of sampling so it could match the particulate samples, 8-10 h (a total of 6-24 L collected in $10 \mathrm{~h}$ ). The thermal desorption tubes for hydrocarbons were analyzed via the Perkin-Elmer automatic thermal desorber (ATD) model 400. This is directly connected to the Hewlett-Packard (HP) $5890 \mathrm{II}$ gas chromatograph with an HP 5971 mass-selective detector (MSD). The ATD transfer connects directly to the $\mathrm{J} \& \mathrm{~W}$ Scientific DB-1 column $(60 \mathrm{~m} \times 0.25 \mathrm{~mm}$ i.d. $\times 1.0 \mu \mathrm{m}$ film thickness) for the analytical separation. Samples were analyzed in full scan or selective-ion monitoring mode (SIM) and quantified by an internal standard quantification method using specialized software: Hewlett-Packard EnviroQuant for GC/MSD analysis.

Formaldehyde, acetaldehyde, and acetone were collected by active air flow using a commercially available collector tube from SKC, Inc. (Cat. No. 226-120, SKC, Inc., Eighty Four, PA). These devices collect formaldehyde and higher analog aldehydes by derivatization with a sorbent material, silica gel coated with 2,4-dinitrophenylhydrazine (DNPH). The tube consists of two sections of DNPH, a $300 \mathrm{mg}$ front and $150 \mathrm{mg}$ backup, as well as an initial section of potassium iodide that acts as an ozone scrubber. Aldehyde samplers were stored at $-4{ }^{\circ} \mathrm{C}$ before analysis. We chose to use this aldehyde sampling tube designed for higher flow rates to obtain sufficient material for analysis with our $<24 \mathrm{~h}$ sampling times. Our VOC and aldehyde sampling methods represent standard procedures developed and validated by the Environmental Protection Agency (Compendium Methods TO-17 and TO-11A, respectively) for general environmental sampling in polluted areas where ozone, other oxidants, and $\mathrm{NO}_{x}$ are common. Collectors have treatments to remove ozone. However, small losses can occur when there are high background levels. 
As expected, duplicate samples showed a pattern of increased variability at low concentrations near the limit of detection. There were a small number of breakthrough tests performed, and the methylated alkanes were the only compounds that showed evidence of $>10 \%$ breakthrough under our hydrocarbon sampling protocol. However, the breakthrough was associated only with high-humidity sampling conditions. A small number of blank tubes were spiked with known amounts of VOCs and analyzed to determine the efficiency of recovery. Percent recovery for all but 1,3-butadiene (79\%) was at least $80 \%$. The alkanes and aromatic compounds had $83-91 \%$ recoveries, and none of the recoveries were significantly different from $100 \%$. The standard deviations on these lab experiments are of the same magnitude as those in the duplicate measurements. Similar findings were obtained for the aldehyde sampling.

The number of values less than the limit of detection (LOD) are provided in Table A-2, Supporting Information. With the exception of 1,3-butadiene and methyl tertiary-butyl ether (MTBE), all VOCs and aldehydes were above the limit of detection for $>85 \%$ of the attempted samples. For the purposes of the exposure model, the censored values were substituted with half of the limit of detection observed during the data analysis (LOD/2), as is commonly done with environmental monitoring data $(19,20)$.

A variety of problems occurred during the sampling activities, with high humidity and rain being the most common issue leading to sampling losses. The moisture was condensing or collecting in the ozone prefilter and sometimes in the DNPH tube, ruining the aldehyde sample. Water condensation in the hydrocarbon collector was also a problem, because it became difficult to dry out the sorbent tubes with our standard drying procedure. Overall, we obtained concentration values for $85 \%$ of aldehyde samples attempted, $77 \%$ of the background samples (outdoors and lowest concentrations), and $98 \%$ of the in-vehicle samples. The overall success rate for the VOCs was $97 \%$, with $96 \%$ for outdoor background samples and $98 \%$ for in-vehicle samples. The outdoor samples attempted in Miami, Hagerstown, Houston, and Laredo had substantial losses because of high moisture in the air (either high humidity and/or heavy rain). Since these weather conditions were unrelated to the exposure characteristics of concern, it is unlikely that the missing observations would result in biased exposure estimates.

\section{Data Analysis}

The concentration data were approximately log-normal and have been log-transformed where necessary to meet the normality assumptions of linear regression modeling. All of the statistical analyses were performed using STATA Version 8.2, College Station, TX. Nonparametric statistical tests are used to compare median differences across smokers (Wilcoxon Rank Sum) and locations (Kruskal-Wallis), as well as to assess correlations (Spearman $r$ ). The benzeneto-toluene ratio is examined as a measure of proximity and intensity to traffic source emissions.

A structural equation model (SEM) was used to define particulate exposures in the larger TrIPS study of 36 terminals that collected $\mathrm{EC}$ and $\mathrm{PM}_{2.5}$ data for both personal and work areas (i.e., dockworker and loading dock area, mechanic and mechanic shop area, etc.), as well as yard background measurements (15). The SEM for VOCs and aldehydes is constructed with a focus on predicting average work area exposures, since personal monitoring (dockworker, mechanic, etc.) was not conducted for these compounds. In this application, SEMs provide a way to analyze the data that reflects the natural hierarchy present in our sampling scheme, accounting for the directionality of exposures (yard background $\rightarrow$ indoor work area). In particular, the nature of our sampling plan imposes a complex covariance structure on the collected data since the concurrent measurements taken by stationary work area samplers and external measurements of yard background conditions are not independent. Different sources contribute simultaneously to the measurements observed at different locations within the terminals during the same time periods. Of particular statistical concern is the correlation among the error terms, 
as well as the correlation between the response variables and the error terms. Both of these conditions violate necessary assumptions for simple linear regression modeling.

Where multiple background measurements were collected during a single session, the average value was calculated and matched with the concurrent indoor work area measurement from the loading dock or mechanic shop. The following equations were estimated simultaneously: $\ln ($ WorkAreaConc $)=\beta_{10}+\beta_{11} \ln ($ YardBackground $)+$

$$
\beta_{12} \mathrm{Job}+\varepsilon
$$

$$
\begin{aligned}
& \ln (\text { YardBackground })=\beta_{21}(\text { Temperature })+\beta_{22} \\
& (\text { Windspeed })+\beta_{23}(\text { RoadDistance })+\beta_{24-26} \\
& \text { (RegDummy })+\eta
\end{aligned}
$$

WorkAreaConc is the concentration observed in a given work environment (loading dock or mechanic shop), YardBackground is the concentration observed in the yard (representing background conditions), Windspeed is the average windspeed in miles/h, Job is equal to 1 in the loading dock and 0 in the mechanic shop, Temperature is measured in Celsius, RoadDistance represents the distance in meters to the nearest major road, and RegDummy is the location effect represented by the three census regions where the data were collected (there were no site visits conducted in the South, the fourth census region). Since these census variables are included independently as dummy variables $(0-1)$, the coefficients $\left(\beta_{24-26}\right)$ individually test the hypotheses that the regional constant is 0 . For this reason, the overall constant has been dropped from eq 2 . This has no effect on the other coefficients in the model; however, interpretation of the regional variables must be made using the hypothetical null region as the baseline. Finally, since the determinants of driver exposures are essentially different from those of on-site terminal workers and present unique challenges (i.e., defining exposure along a given route), a separate model is currently in progress for this exposure scenario and only summary statistics and comparisons for drivers are provided here.

\section{Results}

\section{Summary Statistics}

Summary statistics for the VOCs and aldehydes, as well as particulates $\left(\mathrm{EC}\right.$ and $\left.\mathrm{PM}_{2.5}\right)$ for comparison purposes, are provided in Tables 1 and 2. Median driver exposures were significantly higher for smokers than for nonsmokers for particulates and certain VOCs and aldehydes, including methylcyclohexane, 1,3-butadiene, benzene, styrene, and acetaldehyde $(p<0.01)$. The differences across the four locations (yard background, driver, loading dock, and mechanic shop) for all concentrations were statistically significant $(p<0.01)$. While the yard background provided the lowest exposures of all sampled locations, the area of highest exposures varied: the shop was consistently elevated for many of the VOCs including the xylenes, alkanes, acetone, and particulates; the loading dock had relatively high concentrations of 1,3-butadiene and aldehydes, as well as the highest toluene-to-benzene ratio; and nonsmoking driver exposures were elevated for benzene, MTBEs, styrene, and hexane.

\section{Relationship with PM Mass}

Table 3 lists the VOC and aldehyde correlations with EC and Py.5. Loading dock and yard background $\mathrm{EC}$ and $\mathrm{PM}_{2.5}$ levels are highly correlated with many VOCs and aldehydes (50\% with Spearman $r>0.5$ and $75 \%$ with $r>0.4$ ), while nonsmoking driver EC and $\mathrm{PM}_{2.5}$ levels were only correlated with a few aromatics, primarily benzene $(r=0.4-0.5)$. VOCs and aldehydes in the mechanic shop were correlated with EC but not $\mathrm{PM}_{2.5}(r=0.4-0.9$ where significant), with the exception of acetaldehyde, which was significantly correlated only with $\mathrm{PM}_{2.5}(r=0.6)$. 


\section{SEM Exposure Model}

Table 4 provides the SEM results for a representative set of VOCs and aldehydes: 1,3butadiene, benzene, toluene, and formaldehyde. See Tables A-3 and A-4, Supporting Information, for the summary statistics for the predictor variables and yard background concentrations by census region. The concentration values have been log-transformed, and interpretation of the coefficients must be made within the context of a multiplicative model. To facilitate the interpretation of coefficients in terms of effect sizes, the \% impact from a onestandard deviation rise in significant predictor variables or \% difference between the mechanic shop and the loading dock for "job" is presented in parenthesis along with the estimated coefficient. For the regional census variables, the multiplicative effect sizes are presented.

The SEM approach provided a good fit for some of the VOC and aldehyde exposure models, with $R^{2}$ s ranging from 0.2 to 0.9 . Increases in background concentrations significantly elevate work area exposures for benzene and 1,3-butadiene (51 and 76\%, respectively), and the model predicts elevated exposures in the loading dock over the mechanic shop for all exposures (increased 70-229\%). Higher temperature levels significantly increase expected background concentrations of formaldehyde (increased 23\%) with the opposite effect for 1,3-butadiene (decreased $41 \%$ ), and wind speed is significantly negative (higher wind speed predicts lower levels) for all concentrations (decreased 13-39\%). The distance to a major road is only significant for toluene and benzene (decreased $42 \%$ and 51\%, respectively), although formaldehyde has the expected negative sign, with increasing distance associated with lower background concentration levels observed at the terminals. The census dummies provide evidence of regional variability across the United States, with significant regional effects for all but butadiene. We also examined the predictive strength of the SEM exposure models with a series of scatter plots depicting the observed versus fitted concentrations, which provide further evidence of a strong linear association (see Figure A-3, Supporting Information).

\section{Discussion}

This paper summarizes and compares VOCs and aldehydes in three exposure environments: (i) background concentrations observed in the yard; (ii) indoor work area concentrations in the mechanic shop and loading dock; and (iii) on-road driver concentrations. Summary statistics are provided for all locations, while the statistical modeling effort focuses only on on-site terminal exposures and excludes drivers. Our results suggest that the level of occupational exposure to VOCs and aldehydes, as well as its correlation to PM mass, varies significantly across sampling locations. The multilayer statistical approach provides a good fit for predicting work area exposure as a function of background levels, job, weather conditions, proximity to a major road, and terminal location.

Diesel exhaust is a complex chemical mixture of hundreds of constituents in both gas and particulate forms, many of which are also present in engine exhaust from other fuel sources, such as gasoline and propane. However, the relative composition of these compounds across work locations, as well as the relationship with particulates, is indicative of the source characteristics present in the different work area and background settings. The mechanic shop is dominated by low-load and startup diesel emissions, as well as low molecular weight vapors from small amounts of fuel drips and cleaning solvents. In this semienclosed work environment where diesel is the primary source of exposure (as opposed to gasoline or LPG powered emissions), VOCs and aldehydes are highly correlated with EC but not $\mathrm{PM}_{2.5}$. This location also provided the highest exposures to xylenes, alkanes, acetone, and particulates. These relationships are representative of diesel as the primary source in this microenvironment, with the additional influence of cleaners, degreasers, etc. 
The loading dock is dominated primarily by emissions from LPG forklift vehicles, where many forklifts may be operating concurrently within a small semienclosed work area. These heavily used vehicles are driven hard under varying loads, which may affect their emissions. Also, even though the forklifts are powered by a "clean" fuel, they are heavily used, and with age and wear, it is possible that emissions might intensify (deposits of black soot can be noted around the exhaust openings on the older units). However, in this investigation, we did not collect data regarding forklift age, and this hypothesis remains untested. The loading dock experienced the highest median concentrations of 1,3-butadiene and aldehydes of any of the sampling locations. The majority of loading dock VOC and aldehyde concentrations were highly correlated with both $\mathrm{EC}$ and $\mathrm{PM}_{2.5}$, which is partially the result of the mix of engine exhaust sources present in this work environment. Unfortunately, forklifts and diesel sources cannot be directly distinguished, and the direct contributions are expected to differ because of proximity to the sources. For example, large truck terminals can have as many as 4-12 forklifts operating at one time in a relatively small, semiconfined area of a loading dock, and trailers are positioned to minimize the distance driven by forklifts. Furthermore, penetration of diesel emissions from trucks in the terminal yard and background air pollution may also enter the work area through the large open doors on either side of the loading dock.

Driver exposures are a mix of car and truck emissions associated with driving in traffic on metro area highways and streets, and these provided the highest exposure scenarios for benzene, MTBEs, styrene, and hexane. P\&D driver exposures to particulates are not highly related to the majority of VOCs and aldehydes, although there is some correlation with aromatics (benzene, $r>0.4$ ). This association with aromatics is likely the result of the overall traffic influence on driver exposures. Finally, yard background measurements of VOCs and aldehydes, which provided the lowest concentrations of all the monitored locations, showed a relatively strong correlation with both $\mathrm{EC}$ and $\mathrm{PM}_{2.5}$. This is likely indicative of the presence of traffic and other sources of air pollution effecting terminal background exposures.

The prediction model developed to describe on-site work area exposures using an SEM approach was consistent with an earlier study of particulate exposure in the trucking industry (17) and provided a good fit for some of the VOC and aldehyde exposure models $\left(R^{2}=0.2-\right.$ $0.9)$. In this application, SEMs provides a way to analyze the data that reflects the natural hierarchy present in our sampling scheme, accounting for the directionality of exposures (yard background $\rightarrow$ indoor work area). The model significantly predicted terminal work area exposures using yard background concentrations and information on work location (mechanic shop and loading dock), while the yard background exposures were simultaneously predicted by weather effects (temperature and windspeed), regional location of the terminal, and proximity to a major road.

The concentration ratio of toluene to benzene has been used previously to predict proximity and intensity of traffic source emissions (21), since toluene is more reactive in the open air and decays at a much faster rate than benzene as distance from the mobile source increases. A ratio of approximately 2:1 has been shown at sampling locations near traffic sources, while the ratio tends toward 1 as distance increases (22). Our results are consistent with a pattern of intense proximate traffic sources, with a ratio slightly $>3$ for both the yard background and the in-cab driver samples. The highest ratios were observed in the indoor work areas, with median values of 4.2 in the mechanic shop and 6.2 in the loading dock.

While a number of studies have measured exposure to VOCs and aldehydes (13,14,23-29), none have concentrated specifically on an occupational setting with intense and prolonged exposure to diesel exhaust and exhaust from other combustion sources. However, a few studies have focused on VOC and aldehyde exposures in similar microenvironments to those observed in our study, including background, traffic, and transportation depots. These studies include 
exposure data from the U.K. (14), Mexico (23), and Hong Kong (24), which are provided in Table 5 for comparison. Our driver exposures are lower than the least exposed microenvironment in the U.K. study (bus station), and exposure to formaldehyde and acetaldehyde is somewhat higher for our drivers compared with roadside observations made in Mexico and Hong Kong. However, our measurements were made in trucks that mainly traveled in U.S. cities during non-rush hour times, while traffic density was higher in the nonU.S. comparison sites and, consequently, more likely to be associated with greater emissions. Also, our locations did not have the same mix of vehicle types since diesel vehicle use is more common in cities outside the U.S. Finally, the elevated levels of formaldehyde and acetaldehyde might reflect emissions from the engine of the truck, as opposed to the roadside locations monitored in the comparison studies.

Measured concentrations of VOCs and aldehydes were above the limit of detection for at least $85 \%$ of the attempted samples with the exception of MTBE and 1,3-butadiene. MTBE values below the limit of detection are likely the result of local and state policies banning or restricting its use as a fuel additive. Nearly $40 \%$ of U.S. states are listed by the EPA as having either a partial or complete ban on the addition of MTBE in fuel during the study period (30), including four of our sampling locations. There is a statistically significant impact from the ban on MTBE concentrations at the terminals and in truck cabs, with significantly higher concentrations noted in states without a ban (Table A-5, Supporting Information). Therefore, given the discontinued use of this chemical as a fuel additive in some of our locations, it is very likely that the observed concentrations would be at or near zero, i.e., there is no evidence to suggest an analytical issue prompting the relatively high percentage of nondetects for MTBEs.

In contrast, the high percentage of below the LOD measurements for 1,3-butadiene is more likely an analytical issue and not the result of its absence in the background air conditions. 1,3Butadiene differs considerably from the other VOCs with respect to its adsorption and desorption characteristics in sampling materials, as well as its susceptibility to decomposition and artifact formation (13). The generally low levels of 1,3-butadiene observed in our microenvironments further complicated the data analysis, since our method proved inefficient in capturing low levels of this chemical. To illustrate, although the log-log relationship between benzene and 1,3-butadiene was very strong at detected levels of 1,3-butadiene in all four of the monitored microenvironments $\left(R^{2}=0.2-0.9\right.$, see Figure A-4, Supporting Information), this relationship was inconsistent for values close to or below the limit of detection (i.e., nondetects for 1,3-butadiene spanned the entire range of benzene).

Finally, we demonstrate the feasibility of measuring VOCs in a number of different microenvironments and provide evidence of significant variability in exposure patterns across job descriptions. Our findings suggest that it is possible to design an epidemiologic study to assess the relationship between exposure to VOCs and select health outcomes in trucking company workers. The variation in background exposures described by weather effects, regional location of the terminal, and proximity to a major road in the SEM model might be used to predict historical exposures and to study relationships with selected chronic health effects. Alternatively, variation in work area exposures attributable to these factors might be explored to assess shorter-term relationships with changes in respiratory function or other short-term outcomes using a repeated measures design.

\section{Supplementary Material}

Refer to Web version on PubMed Central for supplementary material. 


\section{Acknowledgements}

We would like to acknowledge the contribution of the other members of the Trucking Industry Particle Study, Drs. Douglas W. Dockery and Frank E. Speizer, and to acknowledge Kevin Lane and Jonathan Natkin for excellent field work and technical data support. We would also like to thank the International Brotherhood of Teamsters Safety and Health Dept. (LaMont Byrd) and the participating companies. This work was supported by NIH/NCI R01 CA90792 and HEI 4705-RFA03-1/04-1.

\section{Literature Cited}

1. Bhatia R, Lopipero P, Smith AH. Diesel exhaust exposure and lung cancer. Epidemiology 1998;9:8491. [PubMed: 9430274]

2. Lipsett M, Campleman S. Occupational exposure to diesel exhaust and lung cancer: A meta-analysis. Am J Public Health 1999;89:1009-1017. [PubMed: 10394308]

3. California Air Resources Board. Identification of Diesel Exhaust as a Toxic Air Contaminant; Amendment to Section 93000, Title 17, California Code of Regulations. 1998. http://www.arb.ca.gov/regact/diesltac/diesltac.htm

4. IARC. International Agency for Research on Cancer; Lyon, France: 1989. Diesel and gasoline engine exhausts and some nitroarenes. http://monographs.iarc.fr/ENG/Monographs/vol46/volume46.pdf

5. HEI. Health Effects Institute; Cambridge, MA: 1995. Diesel exhaust: a critical analysis of emissions, exposure and health effects. http://www.healtheffects.org/Pubs/diesum.htm

6. WHO. Diesel fuel and exhaust emissions. World Health Organization; Geneva, Switzerland: 1996.

7. U.S. EPA. Health assessment document for diesel engine exhaust. U.S. Environmental Protection Agency; Washington DC: 2002. http://cfpub.epa.gov/ncea/cfm/recordisplay.cfm?deid=29060

8. International Life Sciences Institute (ILSI). ILSI Risk Science Institute workshop: The relevance of the rat lung response to particle overload for human risk assessment. In: Gardner, DE., editor. Inhalation Toxicol. 12. 2000. p. 1-17.

9. U.S. EPA. Integrated Risk Information System (IRIS). U.S. Environmental Protection Agency; Washington, DC: http://www.epa.gov/iris/

10. Laden F, Hart JE, Smith TJ, Davis ME, Garshick E. Cause Specific Mortality in the Unionized U.S. Trucking Industry. Environ Health Perspect. in press

11. Hart JE, Laden F, Schenker MB, Garshick E. Chronic Obstructive Pulmonary Disease Mortality in Diesel-Exposed Railroad Workers. Environ Health Perspect 2006;114(7):1013-1017. [PubMed: 16835052]

12. Delfino R. Epidemiologic Evidence for Asthma and Exposure to Air Toxics: Linkages between Occupational, Indoor, and Community Air Pollution Research. Environ Health Perspect 2002;110 (Supp 4):573-589. [PubMed: 12194890]

13. Kim YM, Harrad S, Harrison RM. Levels and sources of personal inhalation exposure to volatile organic chemicals. Environ Sci Technol 2002;36:5405-5410. [PubMed: 12521168]

14. Kim YM, Harrad S, Harrison RM. Concentrations and Sources of VOCs in Urban Domestic and Public Microenvironments. Environ Sci Technol 2001;35:997-1004. [PubMed: 11347947]

15. Davis ME, Smith TJ, Laden F, Hart JE, Ryan LM, Garshick E. Modeling particle exposure in U.S. trucking terminals. Environ Sci Technol 2006;40:4226-4232. [PubMed: 16856739]

16. Smith TJ, Davis ME, Reaser P, Hart JE, Laden F, Heff A, Garshick E. Overview of particulate exposures in the US trucking industry. J Environ Monit 2006;8(7):711-720. [PubMed: 16826284]

17. Garshick, E.; Smith, TJ.; Laden, F. Diesel Epidemiology Working Group. Research Directions for Improved Estimates of Human Exposure and Risk from Diesel Exhaust. Health Effects Institute; Cambridge, MA: 2002. Quantitative assessment of lung cancer risk from diesel exhaust exposure in the US trucking industry: A feasibility study. http://www.healtheffects.org/Pubs/DieselSpecialReport02.pdf

18. Brown, J.; Shirey, B. A Tool for Selecting an Adsorbent for Thermal Desorption Applications. Supelco; Bellefonte, PA: 2001.

19. Lapina K, Paterson KG. Assessing source characteristics of PM2.5 in the eastern United States using positive matrix factorization. J Air Waste Manage Assoc 2004;54:1170-1174. 
20. Ramadan Z, Song XH, Hopke PK. Identification of sources of Phoenix aerosol by positive matrix factorization. J Air Waste Manage Assoc 2000;50:1308-1320.

21. Gelencser A, Siszler K, Hlavay J. Toluene-benzene concentration ratio as a tool for characterizing the distance from vehicular emission sources. Environ Sci Technol 1997;31:2869-2872.

22. Smith LA, Mukerjee S, Monroy GJ, Keene FE. Preliminary assessments of spatial influences in the Ambos Nogales region of the US-Mexican border. Sci Total Environ 2001;276:83-92. [PubMed: 11516141]

23. Serrano-Trespalacios, PI.; Ryan, L.; Spengler, JD. J Exposure Anal Environ Epidemiol. 14. 2004. Ambient, indoor, and personal exposure relationships of volatile organic compounds in Mexico City metropolitan area; p. 118-132.

24. Ho KF, Lee SC. Identification of atmospheric volatile organic compounds (VOCs), polycyclic aromatic hydrocarbons (PAHs) and carbonyl compounds in Hong Kong. Sci Total Environ 2002;289:145-158. [PubMed: 12049391]

25. Kinney PL, Chillrud SN, Ramstrom S, Ross J, Spengler JD. Exposures to multiple air toxics in New York City. Environ Health Perspect 2002;110(S4):539-546. [PubMed: 12194883]

26. Lee SC, Chiu MY, Ho KF, Zou SC, Wang X. Volatile organic compounds (VOCs) in urban atmosphere of Hong Kong. Chemosphere 2002;48:375-382. [PubMed: 12146626]

27. Ho KF, Lee SC, Guo H, Tsai WY. Seasonal and diurnal variations of volatile organic compounds (VOCs) in the atmosphere of Hong Kong. Sci Total Environ 2004;322:155-166. [PubMed: 15081745]

28. Seila RL, Main HH, Arriaga JL, Martinez G, Ramadan AB. Atmospheric volatile organic compound measurements during the 1996 Paso del Norte Ozone Study. Sci Total Environ 2001;276:153-169. [PubMed: 11523535]

29. Anderson MJ, Miller SL, Milford JB. Source apportionment of exposure to toxic volatile organic compounds using positive matrix factorization. J Anal Environ Epidemiol 2001;11:295-307.

30. U.S. EPA. State Actions Banning MTBE EPA420-B-04-009. U.S. Environmental Protection Agency; Washington, DC: 2004. http://www.epa.gov/MTBE/420b04009.pdf 
TABLE 1

Background Values $\left(\mu \mathrm{g} / \mathrm{m}^{3}\right)^{a}$

\begin{tabular}{|c|c|c|c|c|}
\hline & obs & mean & median & SD \\
\hline trimethylpentane & 432 & 0.71 & 0.43 & 0.79 \\
\hline dimethylpentane & 432 & 0.38 & 0.24 & 0.47 \\
\hline 2-methylhexane & 432 & 0.64 & 0.42 & 0.95 \\
\hline methylpentane & 432 & 1.60 & 1.04 & 2.28 \\
\hline 3-methylhexane & 432 & 0.76 & 0.48 & 1.28 \\
\hline methylcyclohexane & 432 & 0.46 & 0.27 & 0.68 \\
\hline hexane & 161 & 1.70 & 1.01 & 1.86 \\
\hline 1,3-butadiene & 432 & 0.20 & 0.12 & 0.45 \\
\hline benzene & 432 & 1.24 & 1.01 & 0.87 \\
\hline ethylbenzene & 432 & 0.56 & 0.40 & 0.53 \\
\hline$m, p$-xylene & 432 & 1.85 & 1.36 & 1.69 \\
\hline$o$-xylene & 432 & 0.66 & 0.46 & 0.63 \\
\hline styrene & 432 & 0.26 & 0.15 & 0.36 \\
\hline toluene & 432 & 3.67 & 2.77 & 3.43 \\
\hline toluene/benzene & 432 & 3.0 & 2.7 & $\mathrm{n} / \mathrm{a}$ \\
\hline MTBE & 432 & 0.27 & 0.01 & 0.53 \\
\hline acetone & 345 & 2.62 & 1.75 & 3.07 \\
\hline acetaldehyde & 345 & 2.42 & 2.06 & 2.45 \\
\hline formaldehyde & 345 & 3.33 & 3.22 & 1.75 \\
\hline elemental carbon & 432 & 0.83 & 0.57 & 0.77 \\
\hline $\mathrm{PM}_{2.5}$ & 427 & 11.67 & 9.30 & 14.63 \\
\hline
\end{tabular}

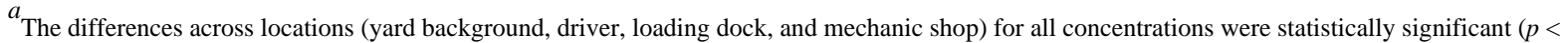
0.01) using Kruskal-Wallis nonparametric comparison tests. 


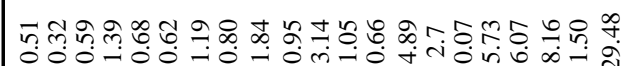

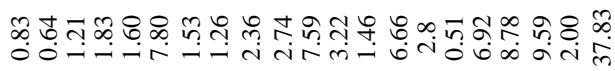

돈

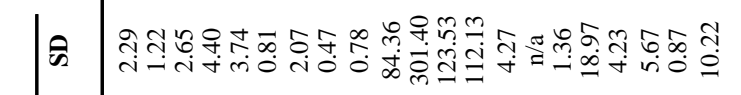

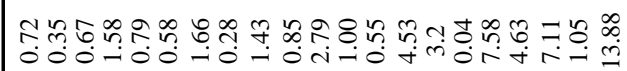

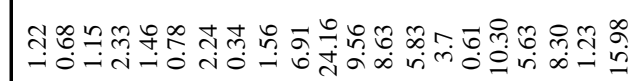

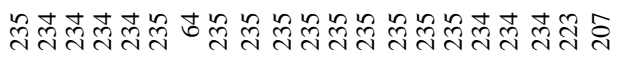

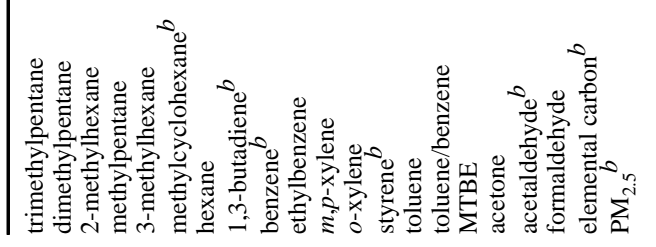




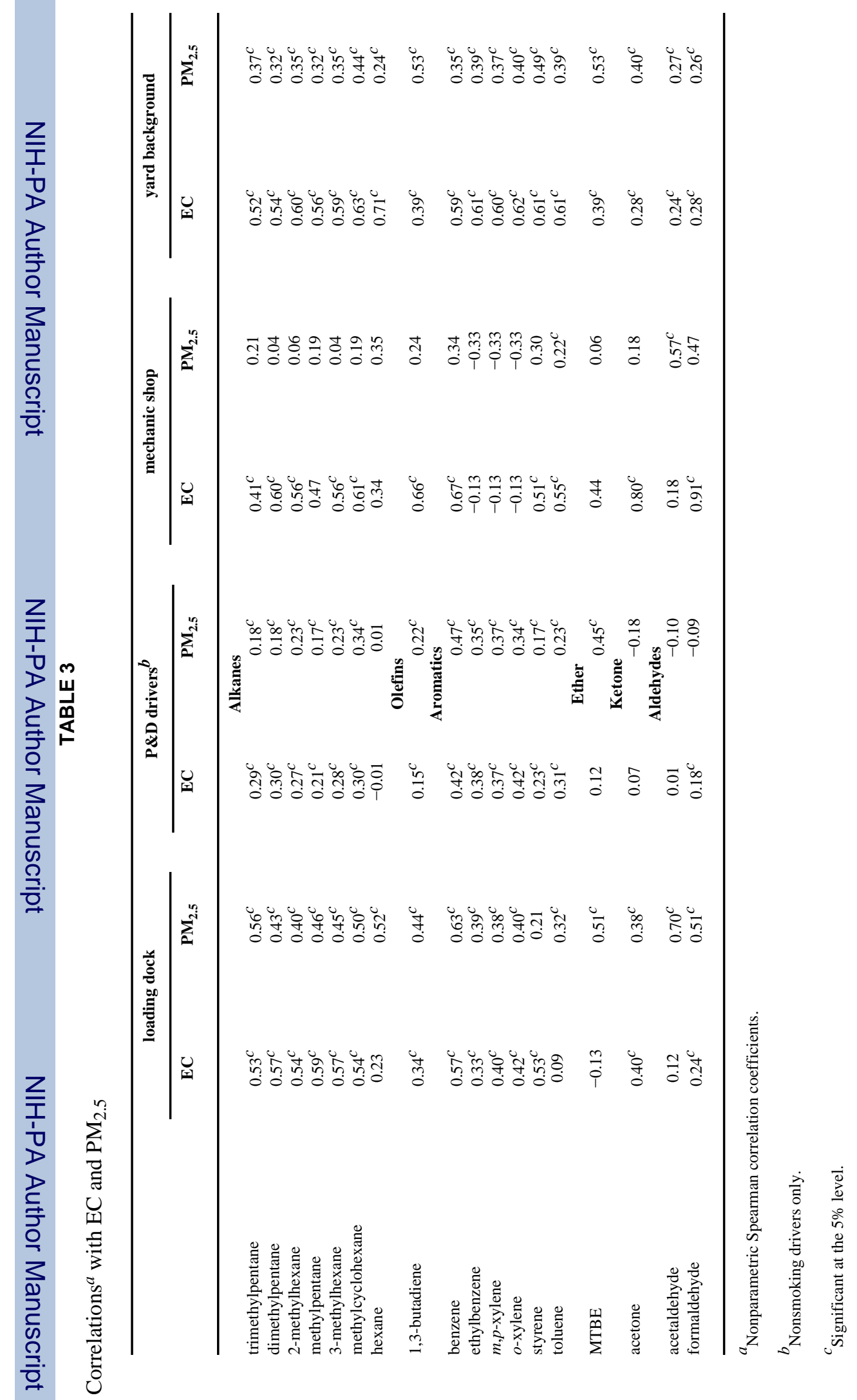


TABLE 4

SEM Regression Results for Select VOCs and Aldehydes ${ }^{a}$

\begin{tabular}{|c|c|c|c|c|}
\hline & 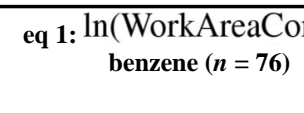 & $\begin{array}{c}10+\beta_{11} \ln (\text { YardB } \\
\text { 1,3-butadiene }(n= \\
\text { 75) }\end{array}$ & $\begin{array}{l}\text { ind })+\beta_{12} \text { Job }+\varepsilon \\
\text { toluene }(n=75)\end{array}$ & $\begin{array}{c}\text { formaldehyde }(n=) \\
70)\end{array}$ \\
\hline yard background & $0.79(\uparrow 51 \%)^{b}$ & $0.48(\uparrow 76 \%)^{b}$ & 0.46 & 0.35 \\
\hline job & $0.53(\uparrow 70 \%)^{b}$ & $0.99(\uparrow 169 \%)^{b}$ & $1.19(\uparrow 229 \%)^{b}$ & $0.99(\uparrow 169 \%)^{b}$ \\
\hline constant & -0.26 & $-0.81^{b}$ & 0.34 & 1.55 \\
\hline RMSE & 0.63 & 0.71 & 1.22 & 0.84 \\
\hline \multirow{2}{*}{\multicolumn{5}{|c|}{ eq 2: $\ln ($ YardBackground $)=\beta_{21}($ Temperature $)+\beta_{22}($ Windspeed $)+\beta_{23}($ RoadDistance $)+\beta_{24-6}($ RegDummy $)+\eta$}} \\
\hline & & & & \\
\hline temperature & $\begin{array}{l}\text { benzene } \\
0.01\end{array}$ & $\begin{array}{l}\text { 1,3-butadiene } \\
-0.05(\downarrow 41 \%)^{b}\end{array}$ & $\begin{array}{c}\text { toluene } \\
0.01\end{array}$ & $\begin{array}{l}\text { formaldehyde } \\
0.02(\uparrow 23 \%)^{b}\end{array}$ \\
\hline windspeed & $-0.09(\downarrow 24 \%)^{b}$ & $-0.09(\downarrow 24 \%)^{b}$ & $-0.15(\downarrow 39 \%)^{b}$ & $-0.04(\downarrow 13 \%)^{b}$ \\
\hline road distance & $-0.0004(\downarrow 51 \%)^{b}$ & 0.0002 & $-0.0003(\downarrow 42 \%)^{b}$ & -0.0001 \\
\hline region 1 (Midwest) & $0.99(2.69)^{b}$ & -0.05 & $2.15(8.58)^{b}$ & $1.22(3.39)^{b}$ \\
\hline region 2 (Northeast) & $1.03(2.80)^{b}$ & $-1.04(0.35)^{b}$ & $2.07(7.92)^{b}$ & $1.37(3.94)^{b}$ \\
\hline region 3 (West) & $1.45(4.26)^{b}$ & 0.06 & $2.78(16.12)^{b}$ & $1.08(2.94)^{b}$ \\
\hline constant $^{c}$ & $\mathrm{n} / \mathrm{a}$ & $\mathrm{n} / \mathrm{a}$ & $\mathrm{n} / \mathrm{a}$ & $\mathrm{n} / \mathrm{a}$ \\
\hline RMSE & 0.40 & 0.68 & 0.53 & 0.37 \\
\hline$R^{2}$ & 0.45 & 0.83 & 0.80 & 0.90 \\
\hline
\end{tabular}

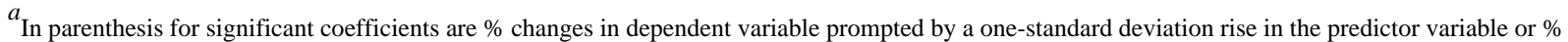
difference between mechanic shop and loading dock for job. For regional census variables, multiplicative effect sizes are presented.

${ }^{b}$ Significant at $5 \%$ level.

${ }^{c}$ The constant has been dropped from eq 2 since all three regional dummy variables are included in the model. This does not effect the coefficients for the other variables, only the interpretation of the regional variables (hypothetical null used as baseline). 


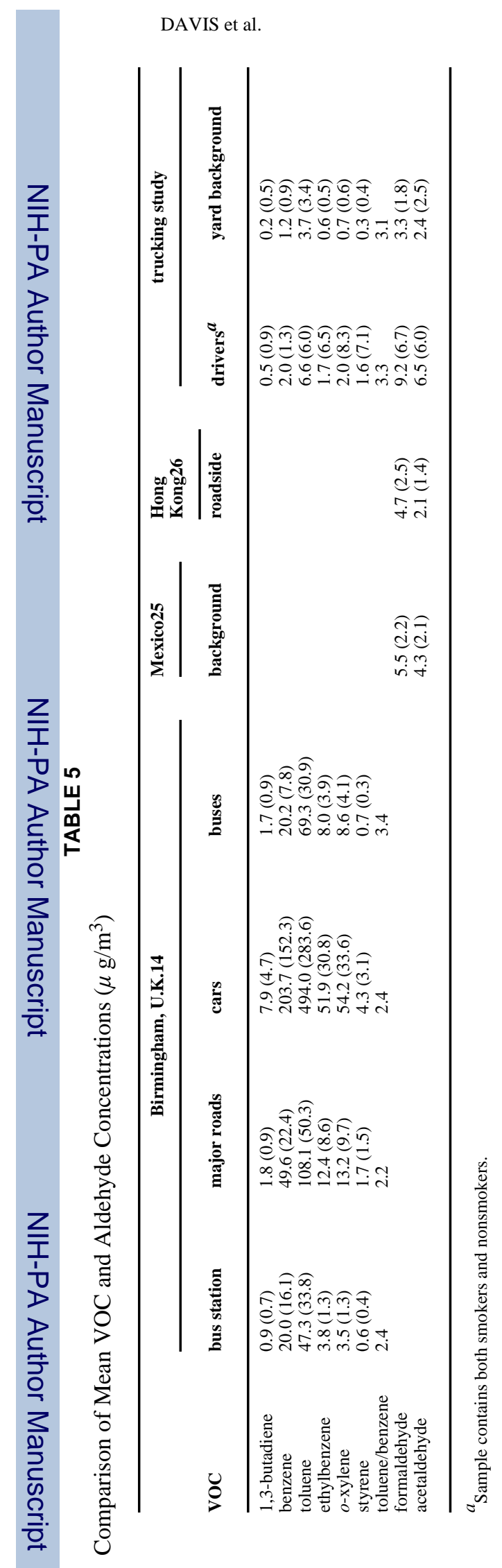

Environ Sci Technol. Author manuscript; available in PMC 2008 May 14. 